\title{
La fase gaditana del ingeniero Antonio Prat
}

\author{
Luis francisco Martinez Montiel *
}

Desde los inicios de la ingenieria militar, sus profesionales estuvieron íntimamente ligados a disciplinas tan dispares como la artillería, la infanteria e incluso la arquitectura. No se producirá hasta mucho despues la delimitación de su actividad, y aún asi no faltarán ejemplos de ingenieros ilustrados que dominen y actuen en más de un campo. Encargados de la defensa del territorio nacional como función primordial, fueron asumiendo además, obligados por el agravamiento de las tensiones en algunas zonas estratégicas, un gran número de tareas cuya vinculación con su cometido profesional no esta muy claro. Así la creación de fortificación y la remodelación de las ya existentes, el desarrollo de canales y caminos, los levantamientos cartográficos, la ejecución de proyectos arquitectóni$\cos$ y urbanisticos y un largo etc, fueron cometidos comunes a su oficio. En mayor o menor medida, y cada uno según su capacidad, actuaron en uno o varios de estos campos '.

A través del memorial que el ingeniero de la Armada don Antonio Prat envió el 2 de marzo de 1815 al secretario de Estado y del Despacho de Marina, relacionando todos los encargos que al margen de las tareas propias de su cuerpo, habia realizado, es posible conocer el amplio campo en que desarrolló su trabajo. Asimismo, este expediente nos aproxima a la trayectoria vital y profesional de uno de los ingenieros que más contribuyó con sus realizaciones a la derrota del ejército francés en la Guerra de la Independencia ${ }^{2}$.

* Instituto Andaluz de Patrimonio Histórico.

1 Sobre los ingenieros militares y sus funciones véase. CAPEL, H.; SANCHEZ, J. E.; MONCADA, O., De Palas a Minerva. La formación cientifica y la estructura institucional de los ingenieros militares en el siglo xvim. Barcelona 1988.

${ }^{2}$ Tanto el Memorial como las certificaciones se hallan en el Archivo Museo don Alvaro de Bazán en el Viso del Marqués. Sección Ingenieros asuntos personales: Antonio Prat. El expediente está fechado el 8 de marzo de 1815. 
Hijo del arquitecto catalán José Prat, nació, según don Vicente Tofiño en 1769, pues cuando en 1790 este lo toma bajo sus órdenes, lo describe como "de buen talento y aplicación a sus veintiun años». Sus primeros estudios los finalizó en Barcelona, ingresando muy joven en su Academia militar, donde siguió los estudios matemáticos necesarios para ingresar en el Cuerpo de Ingenieros ${ }^{3}$.

Tras estos primeros años de formación en su tierra natal se trasladó a Cádiz acompañando a su padre. La llegada de José Prat a esta ciudad se supone a mediados de la década de 1780 , cuando por primera vez se le incluye, junto al marqués de Ureña y otros prestigiosos arquitectos, en la junta de facultativos nombrada para resolver el conflicto que planteaba el levantamiento de la fachada principal de la catedral gaditana. Poco después, asentada ya la familia en la ciudad, sustituyó interinamente al arquitecto Miguel de Olivares en la construcción de las pechinas de la cúpula del crucero presentando un proyecto para la fachada, que le era admitido ${ }^{4}$. Una vez en Cádiz, don Antonio Prat continuó su formación en la Academia de Guardias Marinas de la Real Isla de León. En ella realizó el "curso de estudios sublimes", profundizando en aritmética, geometría, trigonometria, cálculo, algebra cartesiana y mecánica práctica y teórica. Además parece seguro que debió seguir otras materias, como las de maniobra, fortificación y dibujo, que también se impartían en dicho centro, pues de ellas dejaria buenas pruebas en su posterior quehacer profesional ${ }^{5}$.

A pesar de su juventud, sus conocimientos debían ser considerables pues cuando en 1790 don Vicente Tofiño lo toma a su cargo para levantar el plano «muy circunstanciado de esta Isla de León con los grupos de edificios que miran al mar desde Santi Vañez hasta el Arsenal de La Carraca" que le habia encargado la Junta del Departamento de Cádiz, queda sorprendido al encontrarlo muy «instruido en matemáticas, tanto en la parte teórica como en la práctica». Además, según Tofiño, poseía una

\footnotetext{
${ }^{3}$ Esta certificación la firma en La Real Isla de León don Vicente Tofiño el 23 de noviembre de 1790, encontrándose en el expediente citado en la nota anterior.

${ }^{4}$ Sobre la intervención de José Prat en la fábrica de la Catedral gaditana consúltese Antón SOlÉ, Pablo, La Catedral de Cádiz. Estudio histórico y artistico de su arquitectura. Cádiz 1975.

${ }^{5}$ La certificación del aprovechamiento en el curso de estudios sublimes la firma don Cipriano Vimercati como director de la Academia de Guardias Marinas de la Real Isla de León el 24 de julio de 1794. Aquella se encuentra en el expediente citado en la nota $n .^{\circ} 2$. Sobre la citada Academia puede verse, Martinez Montiel, Luis Francisco, "Las Casas de Reyna y Sacramento: primeros establecimientos de la Real Compañia de Guardias Marinas en la Isla de León” en Revista de Historia Naval. Año V. Número 18. Madrid 1987, págs. 5772 .
} 
"gran habilidad para la arquitectura civil y militar, dibuxo de línea y figura $y$ otros muchos ramos que aunque no son necesarios dan valor al principal objeto de la Profecion" ${ }^{6}$.

Tras la culminación de los correspondientes estudios ingresó plenamente en la carrera militar, obteniendo el grado de alferez de Fragata de la Real Armada el 10 de julio de 1790. A partir de este instante comenzó a realizar funciones como agregado al cuerpo de ingenieros de marina que se había creado unos años antes ${ }^{7}$. Sin embargo, no seria hasta 1794 , cuando "al tenor del articulo 441 de la ordenanza de arsenales» se le encontraría muy preparado en los temas de su profesión, siendo considerado por don Cipriano Vimercanti, director de la Academia de Guardias Marinas, como «a proposito para servir con mucha utilidad a S.M. en el cuerpo de Yngenieros de Marina" ". Pese a este nombramiento oficial, su reconocimiento como ingeniero de prestigio era anterior, pues ya a finales de octubre de 1793, cuando el marqués de Ureña se traslada a Madrid, se encargó Prat de la dirección de la obra del Real Observatorio Astronómico de la Isla de León durante los trece meses que duró la estancia de aquel en la capital. A lo largo de este periodo fue Prat quien se encargó de confeccionar y firmar todos los partes de obras, incluido el de la colocación de la primera piedra del edificio. Su labor de control en la fábrica del Observatorio no concluyó con el regreso del marqués de Ureña, pues continuó en ella hasta su culminación en $1797^{\circ}$.

Durante los cuatro años que duró su actuación en el Observatorio compaginó la labor con la realización de otra serie de proyectos. Entre ellos tan sólo conocemos con certeza los levantamientos de cartas geográficas de los "pueblos de la provincia marina de Sanlucar de Barrameda" y de Sevilla realizado ambos en $1794^{10}$. Pero sin lugar a dudas debió intervenir en muchos otros pues en el año de 1803 el Departamento reconocia sus méritos en más de 80 comisiones, considerándolo apto para que se encargara de cualquier dirección de obra, a realizar en la zona.

\footnotetext{
${ }^{6}$ Veáse nota $\mathrm{n} .{ }^{\circ} 3$

${ }^{7}$ Con la creación de este nuevo Cuerpo en 1770, los ingenieros militares dejaban de realizar comisiones en obras de arsenales, con lo que se acentuaban las diferencias técnicas y corporativas entre ambos. Cfr. CAPEL, H., Op. cit., pág. 202.

${ }^{8}$ Veáse nota ${ }^{\circ}{ }^{\circ} 2$

${ }^{9}$ Sobre la intervención de Antonio Prat en la construcción del Real Observatorio Astronómico de San Fernando consúltese, Martinez Montiel, Luis Francisco, El Real Observatorio Astronómico de San Fernando (1769-1869). Sevilla 1989.

${ }^{10}$ Esta categoria se recoge en: Servicio Geográfico del Ejército: Cartoteca Histórica. Madrid 1974. Pág. 207. En esta publicación ambos planos se datan en 1754, lo que sin duda es un error en la lectura, pues cronológicamente la fecha más factible es la de 1794.
} 
Asi fue en efecto, pues a partir de ese momento encontramos a don Antonio Prat en numerosos proyectos de la corona. En el verano de 1804 se hace cargo de la obra del Canal Navegable que la Inspección General de Caminos queria abrir para la mejor comunicación entre Chiclana y la Real Isla de León. Sin embargo, el proyecto se paralizaria momentáneamente por los posibles daños que este nuevo Canal podia causar en los caños que rodeaban al Arsenal de La Carraca ${ }^{11}$. Poco después de la paralización, y tras los pertinentes intercambios de oficios entre la Comandancia del Departamento y la Secretaría de Estado, el marqués de la Solana ordenaba a Prat que ejecutase los planos para la limpia y corte de este Canal y que lo recorriese examinando los diversos problemas que podria plantear. Según Prat los daños en los fondos de los caños que circundaban a La Carraca eran fáciles de solucionar. Para ello defendió como paso previo a la realización de la obra el que se «desecharan las aguas del Monte de Chiclana, por fuera de la población que aunque se gaste algo más, produce el útil resultado de asegurar toda la obra del nuevo proyecto o canal, cortando el daño que infaliblemente le causarian las avenidas si no se hiciere así y quita el que cada dia mas se aumentaria en los caños del Arsenal»" ${ }^{12}$.

De esta forma se comenzó la obra, llevando un ritmo considerable su construcción pues el 13 de enero de 1806, el jefe del Estado Mayor del Real Cuerpo de Ingenieros, don Antonio Samper lo felicita porque en el "breve termino de cincuenta y ocho dias quedaran enteramente concluidas mas de doscientas varas del Caño nuevamente abierto con obgeto de unir los Rios de Chiclana y Sancti-Petri» ${ }^{13}$.

Todo este proyecto responde sin lugar a dudas, al deseo de hacer más efectiva la defensa de las islas gaditanas. No hay que olvidar que el mismo año de comenzar aquellos trabajos se había producido la batalla de Trafalgar que habia diezmado enormemente a la Armada. Además, las tensas relaciones con las otras dos grandes potencias, Francia e Inglaterra, hacian presagiar, como de hecho ocurriria poco después, nuevos enfrentamientos bélicos ${ }^{14}$.

"Sobre la dependencia del Arsenal de La Carraca a la limpieza de los caños que la rodean puede consultarse: Barros CANEDA, José Ramón, Arquitectura y Urbanismo de La Carraca durante el siglo xvim. Sevilla 1989.

${ }_{12}$ Las certificaciones de esta obra están firmadas en la Isla de León el 3 de octubre de 1805 por don Joaquin Moreno. Veáse nota $\mathrm{n}^{\circ} 2$.

${ }^{13}$ Certificación recogida en el expediente citado en la nota n. ${ }^{\circ}$. En ella se da cuenta de la carta firmada por don Antonio Samper el 13 de enero de 1807.

${ }^{14}$ Sobre las consecuencias del desastre de Trafalgar en la bahia gaditana veáse, C C AviJo y Clavijo, Salvador, La ciudad de San Fernando. Historia y Espiritu. T. I. San Fernando 1961, pág. 361. 
No comenzaba muy bien el siglo para la bahía gaditana pues unido al desastre de la Armada, principal motor económico de la Isla de León, se expandia una epidemia de fiebre amarilla ${ }^{15}$ que diezmaba aún más su población dejando la zona a expensas de cualquier contingencia. Se hacia cada vez más necesario, ante los nuevos acontecimiertos que se iban desarrollando en España, la preparación de un amplio programa para la defensa de toda la bahia. Es en este campo donde seria fundamental la actuación de don Antonio Prat, llevando a cabo numerosas obras de fortificación en la estratégica zona de la bahia gaditana y más concretamente en la Real Isla de León y en Cádiz.

La situación topográfica de la Isla de León que ya se había tenido en cuenta en 1750 para la traslación del departamento de Marina, se intentará reforzar en este momento con la construcción de nuevas fortificaciones y con las reformas de las ya existentes, que presentaban un estado de casi total abandono ${ }^{16}$. Desde los primeros años del siglo XVIII, cuando se decidia levantar un baluarte defensivo en las dos islas para impendir otro asalto como el llevado a cabo en 1702 para la escuadra anglo-holandesa no se había realizado un plan defensivo tan coherente. Las nuevas construcciones se realizarian bajo la dirección de don Antonio Prat, intentando con ello convertir a la Real Isla de León en la principal fortificación de Cádiz. Asi a los Caños de Sancti-Petri y Rio Arillo, que era dos fosos naturales de dificil acceso se le fueron uniendo nuevas baterias artilleras, que hicieron más impugnables las marismas, tierras pantanosas y salinas que rodeaban a la población ${ }^{17}$.

Como ya se dijo, el desastre de Trafalgar seria el factor clave para estas nuevas construcciones. Así se culminaba en abril de 1806 una bateria para el Cuerpo de artilleria de Brigadas de marina, intentado paliar en lo posible cualquier nuevo enfrentamiento. El levantamiento de esta propiciaba que se felicitara por su «zelo al Yngeniero extraordinario Dn. Antonio Prat y buen cumplimiento del Asentista Agapito Yarza” ${ }^{18}$.

is Sobre la epidemia de fiebre amarilla en las islas gaditanas véase, Clavijo y Clavijo, Salvador, Op. cit., págs. 362 y ss.

${ }^{16}$ Para el traslado del Departamento de Cádiz a la Real Isla de León se puede consultar: Clavijo y Clavijo, Salvador, Op. cit., t. I., pág. 264. Álvarez Martinez, A.; Corzo Sánchez, R.; Giles Pacheco, F.; Pemán Medina, M.; Toscano San Gil, M., San Fernando. Cádiz 1981, pág. 60.

17 Cfr. de Millán Chivite, José Lúis; Pérez Mullet, Fernando: «El conjunto arquitectónico de la Real Isla de León en el cerco y las cortes (1810-1812)", en Boletin del Museo de Cádiz. II. Cádiz 1979-1980, págs. 101-119.

${ }^{18}$ Carta del Señor Bailio don Francisco Gil y Lemus agradeciendo a ingeniero y asentista la construcción de la bateria. Véase la nota $n .{ }^{\circ} 2$. 
La versatilidad de labores anteriormente aludida quedaba de nuevo patente el mismo año de 1806 cuando, tras la muerte don Gaspar de Molina, marqués de Ureña, Prat asumia la dirección interina de las obras de la Nueva Población de San Carlos. En ella continuó la labor desarrollada por su antecesor, haciéndose cargo de los planos y dirección de la obra ${ }^{19}$. Un año después, aparece de nuevo asumiendo el papel de ingeniero en la dirección de las obras de las rampas y barcas que se construian en el caño de Zurraque para facilitar la comunicación a los carruajes y al ganado.

Todos estos preparativos, que le habian ocupado varios años tendrian su culminación en 1808. En tan decisiva fecha para la historia nacional Prat fue llamado para cumplir misiones decisivas, en las que se evidenció su categoría y prestigio profesional, fundamentado en su preparación teórica y en su larga experiencia. Tras la invasión francesa, el estado del Departamento de Marina de la zona de la bahía gaditana era insostenible. Sin caudal en su tesorería era imposible la preparación de la tropa, el arreglo de los presidios o la habilitación de los hospitales. Ante la gravedad de la situación el único recurso que quedaba era pedir ayuda al gobierno de la Nación. Para ello fue comisionado don Antonio Prat, quien "fue en posta á Madrid á instruir á S.M. del Estado del Departamento y de la necesidad de un pronto socorro". La situación se solventó rápidamente recibiendo dos millones de reales, además de una consignación para hacer frente a los casos de urgencia. Más tarde, el 8 de diciembre del mismo año, era comisionado de nuevo por don Joaquín Moreno de Mondragón, comandante general, para dar cuenta a S.M. de la inmediata salida de los batallones y brigadas de Marina para la Campaña. Además llevaba el encargo de averiguar el estado en que se hallaba la Junta Central y el número y posición de los ejércitos propios y de los enemigos.

Entretanto la guerra continuaba y pronto se hicieron necesarios sus servicios en campaña. En un primer momento fue llamado urgentemente a Sevilla, pero su conocimiento de la bahia gaditana y el cariz que iban adquiriendo los acontecimientos aconsejaron su permanencia en la Real Isla de León.

De esta forma, el 14 de febrero de 1809 se le nombraba director de las obras de fortificación de la Plaza, labor de la que sólo debia dar cuen-

\footnotetext{
${ }^{19}$ Sobre la Nueva Población de San Carlos véanse, Velasco Garcia, Carmen, Aspectos urbanísticos y arquitectónicos del siglo xvil en San Fernando. Cádiz 1984, pág. 86; VIRGINA Sanz, M. ${ }^{a}$ M., "El marqués de Ureña y el neoclasicismo gaditano", en Goya n. ${ }^{\circ} 151$. Madrid 1979, págs. 19-24. La comunicación de la dirección de la obra a don Antonio Prat tras la muerte del marqués de Ureña se fecha el 12 de diciembre de 1806 . Véase documento $n .{ }^{\circ} 9$ en el expediente ya citado en la nota $n .^{\circ} 2$.
} 
ta a la Junta de Fortificaciones creada en el Departamento. Se le encomendaba "quantas obras de fortificación se están practicando, y deban hacerse en estos puntos, en conformidad del Plan aprobado por la Junta Militar de Cádiz, esforzando los trabajos y acelerando sus progresos" ${ }^{20}$. La necesidad de fortificar la zona cada vez era más urgente dado el rápido avance del enemigo. Así pues, la construcción de fortificaciones comenzó con gran rapidez, participando decisivamente en los trabajos la propia población de la Real Isla de León ${ }^{21}$. El comportamiento de esta, junto al de su director don Antonio Prat, fue muy elogiado por don Agustin Bueno Ortiz, mariscal de campo de los reales ejércitos y director de Plazas y Fortificaciones ${ }^{22}$. Bajo sus órdenes dirigió Prat las defensas de la Isla de León. El enemigo acechaba las cercanias de la ciudad, por lo que con celeridad se iniciaron los preparativos. Así, se realizaron las cortaduras del camino, se derribó el arco central del Puente Zuazo, efectuándose la construcción de los pasos provisionales y las baterias de la «cerca del real» y de la "embocadura del sur del Canal de Sancti-Petri» ${ }^{23}$.

Poco después, batiéndose en retirada, el ejército español se refugia en la Isla de León. A principios de 1810 acompañado del regimiento de "Voluntarios de la Patria" entra el duque de Alburquerque en la ciudad, encargado por la Regencia de su defensa. Su actuación no se hace esperar encargando a Prat que se ocupe de la inundación de las salinas hasta la boca del caño Zurraque, asi como de la destrucción de todos aquellos caminos que esten "dentro de medio tiro de cañon y todos los edificios que esten al mismo medio tiro, y finalmente quanto convenga para hacer impenetrable el terreno que ocupan las salinas". No habria de esperarse mucho para comprobar la efectividad de sus medidas, pues a los pocos dias, el 5 de febrero de 1819 , se inició el asedio francés contra la Isla de León que duraria hasta el 24 de agosto de $1812^{24}$. Durante el periodo que duró el cerco, no dejó don Antonio Prat de trabajar, pues en

${ }^{20}$ Consúltese nota $\mathrm{n}^{\circ} 2$.

${ }^{21}$ Sobre la colaboración de la población isleña en la construcción de las fortificaciones véase, Clavijo y Clavijo, Salvador, Op. cit., págs. 383 y ss.

"? Sobre Agustín Bueno Ortiz consúltese: Capel, H.; Garcia, L.; Moncada, O.; Olive, F.; Quesada, S.; Rodriguez, A.; Sanchez, J. E.; Tello, R., Los ingenieros militares en España. Siglo xvir. Repertorio biográfico e inventario de su labor cientifica y espacial. Barcelona 1983, págs. 85-86.

${ }^{23}$ La relación de estos últimos trabajos bajo la dirección de don Antonio Bueno Ortiz aparecen en el documento $n .^{\circ} 18$ del expediente citado en la nota $n .^{\circ} 2$.

$: 4$ Estas medidas son enumeradas en el documento $n .{ }^{\circ} 20$ del expediente anteriormente citado. Sobre el asedio francés a la Isla de León consuiltese. Clavijo y Clavijo, Salvador, Op. cit., pág. 383; Álvarez Martinez, A., Op. cit., pág. 89; Millan Chivite, J. L. y Pérez Mullet. F., Op. cit., pág. 101. 
los dias del ataque asistió como ayudante del comandante general, colaborando con sus órdenes en la defensa de las baterias.

Poco después, sería comisionado por la Regencia para dirigir las obras de acondicionamiento de los edificios que ocuparon las Cortes en la Isla de León y Cádiz. En la primera ciudad se elegía el Teatro Cómico como salón de las Cortes. Su reforma se basó fundamentalmente en la adecuación del escenario y patio de butacas, quedando los palcos dispuestos como gradas corridas. Asimismo, Prat reconocia los edificios aledaños para ubicar en ellos el cuerpo de guardia ${ }^{25}$. En Cádiz se utilizaría para la instalación de los diputados la iglesia de San Felipe Neri. Su planta eliptica facilitaba la labor de distribución de los diputados pues prácticamente repetía el esquema utilizado en el isleño Teatro de las Cortes. La reforma de la iglesia filipense debió consistir en "alguna construción u ornamentación efimera por lo que el templo salvada aquella coyuntura histórica volvia al estado en que lo dejara Pedro Afanador" ${ }^{26}$.

Al margen de estos encargos de la Regencia, su misión fundamental durante el asalto francés fue la construcción y mantenimiento de las fortificaciones de la Real Isla de León. Entre ellas hay que reseñar las que el nuevo mariscal de campo don Manuel Zapino le encomendara. Durante su mandato volvió a ocuparse de la inundación de las salinas, asi como del establecimiento de la batería del Portazgo y de la dirección de las obras de la batería de San Judas ${ }^{27}$.

Son estas junto con la dirección de las obras en la Nueva Población de San Carlos las últimas de Antonio Prat documentadas en la Real Isla de León. Una vez concluida la contienda, dejó su trabajo en las fortificaciones, iniciando un nuevo período profesional. Sus aciertos en los programas de reforma para convertir en salón de las Cortes el Teatro Cómico de San Fernando y la Iglesia de San Felipe Neri de Cádiz, lo confirmaban como un especialista en tareas de remodelación y rehabilitación.

${ }^{26}$ Sobre las reformas de actual Teatro de las Cortes en San Fernando pueden consultarse Quintana Martinez, Teatro de las Cortes. Monografia histórica (Centenario del 24 de septiembre de 1810 en San Fernando). Cádiz 1910; Lopez Garrido, J. L.; Martinez Montiel, L. F.; Ramirez Malo, F., Guia Histórico Artística de San Fernando. San Fernando 1989. Pág. 53. Para conocer su distribución es interesante la ilustración que aparece en Gautier, T., Voyage en Espagne. Paris 1858.

${ }^{26}$ Cfr. Peman Medina, Maria, "La iglesia de San Felipe Neri. La arquitectura del templo y su significación a la luz de nuevos documentos inéditos", en Boletin del Museo de Cádiz II. Cádiz 1979-1980, pág. 89. Asimismo, es interesante consultar: BELDA, J.; LABRA, R., La Cortes de Cádiz en el oratorio de San Felipe Neri. Madrid, 1912.

${ }^{27}$ Sobre don Manuel Zapino consúltese CAPEL, H., Los ingenieros..., Op. cit., pág. 492. Las nuevas obras en estas baterias aparecen certificadas en el documento $n .{ }^{\circ} 21 \mathrm{del}$ expediente citado en la nota $n .^{\circ} 2$. 
Por ello, el 19 de julio de 1813, a través del Departamento de Cádiz, se le notificaba que habia sido comisionado por el gobierno para que pasase a la villa de Madrid e iniciara "la elección y preparación del edificio que ha de servir en aquella Capital para la reunión de las Cortes". El encargo debió cumplirlo con celeridad, pues al año siguiente se celebraban Cortes en el edificio del que fue Colegio de doña Maria de Aragón ${ }^{28}$.

A partir de este momento su actividad profesional debió realizarse en la capital, pues poco después, el 9 de febrero de 1814, don Pedro Franco, presidente de la Real Academia de San Fernando, le comunicaba en Madrid "que por constarle su ilustración y amor a las artes del instituto", se le nombraba académico de honor. Desde este momento su prestigio en la capital debió aumentar, pues el 3 de julio del mismo año, era nombrado Académico de Mérito en Arquitectura, por la citada institución ${ }^{29}$.

Con la comunicación de este nombramiento, finaliza el memorial que don Antonio Prat enviaba al secretario de Estado, y gracias al cual ha sido posible conocer la primera fase en la trayectoria vital y profesional de uno de los muchos ingenieros militares que, con su esfuerzo y conocimiento, hicieron posible la derrota del ejercito francés y el mantenimiento de un elevado nivel en las obras públicas de una nación que comenzaba timidamente a valorar los triunfos de la llustración.

${ }^{28}$ Véase Fernandez de los Rios, Angel, Guia de Madrid. Manual del madrileño y del forastero. Madrid 1876, pág. 252.

${ }^{29}$ En la Junta Ordinaria del 3 de julio de 1814 que lo nombraba Académico de Mérito firmaban Pedro Franco como presidente, el duque de Granada de Ega, el duque del Parque Castrillo, Antonio Aguado, Juan Adán y Mariano Salvador Maella. Esta comunicación se encuentra en el documento $n .^{\circ} 24$ del expediente citado en la nota $n .{ }^{\circ} 2$. 
